\title{
CARDIAC AMYLOIDOSIS
}

\author{
BY \\ ROBERT BENSON AND J. F. SMITH \\ From the Cardiac Department and the Bernhard Baron Institute of Pathology, \\ The London Hospital \\ Received October 15, 1955
}

Although Wilks (1856) originally postulated the existence of a form of lardaceous disease that appeared to be the primary affection, it was not until 1939 that the features of primary systemic amyloidosis were fully reviewed by Koletsky and Stecher. The disease is less rare than is generally supposed. Thus, only ten cases had been reported in 1930, whereas the number had risen to 48 in 1945, and to 71 in 1950 . This implies a growing awareness of a disease that has hitherto received but little attention in this country. Wild (1886) mentioned cardiac failure in primary amyloidosis but it was Lindsay (1946) who emphasized its common occurrence. Heart failure was present in 56 per cent of 71 cases reviewed by Higgins and Higgins (1950) and this is now accepted as the most important single feature.

The object of this paper is to describe the clinical and pathological findings in five cases of primary amyloidosis presenting with cardiac symptoms, and to direct attention to the disease as a cause of heart failure.

\section{CASE REPORTS}

Case 1. A woman, aged 54, was admitted to hospital with a history of progressive dyspnœa on exertion during the past four years, latterly with swelling of the legs and abdomen. There was severe heart failure with orthopnœa, gross œdema of the legs, a raised venous pressure, liver enlargement, and ascites. Triple rhythm was noted and there were no murmurs. Radiologically there was pulmonary congestion with moderate generalized cardiac enlargement (Fig. 1). The electrocardiogram was of low voltage with a diphasic T wave in leads I and CR7 (Fig. 2). Treatment with fluid and salt restriction, digitalis, and mercurial diuretics resulted in some improvement, and after a month she was discharged to attend as an out-patient. Nine months later she was readmitted with tense œdema extending to the lower abdominal wall. As before, there were no murmurs and a faint third heart sound was present. The blood pressure was $140 / 90 \mathrm{~mm}$. $\mathrm{Hg}$. Radiologically, pulmonary congestion was now more advanced and a small right hydrothorax had developed. The arm-to-tongue circulation time (saccharin method) was prolonged to 41 seconds. The urine contained about one-tenth volume of albumin* on most occasions. Renal and liver function tests were normal. Complete blood counts were also normal. The serum protein level was $5.5 \mathrm{~g}$. per $100 \mathrm{ml}$. with some reduction in the albumin fraction (albumin 2.7 grams, globulin 2.8 grams). During the third and fourth weeks the pulse was observed to be irregular from auricular fibrillation, but the rhythm subsequently returned to normal. Nearly two months after admission there was still massive œdema of the legs with a moderate right hydrothorax. Acupuncture gave partial relief on two occasions with yields of 21 and 12 pints respectively, but her general condition remained stationary and she was eventually discharged home after a stay of three months. Three weeks later she was admitted for the third time. Massive œdema had spread to involve the breasts and upper extremities, and on the following day she became more breathless and died in coma.

* The volume occupied by the albumin when the whole quantity of acidified urine has been boiled and allowed to settle. 


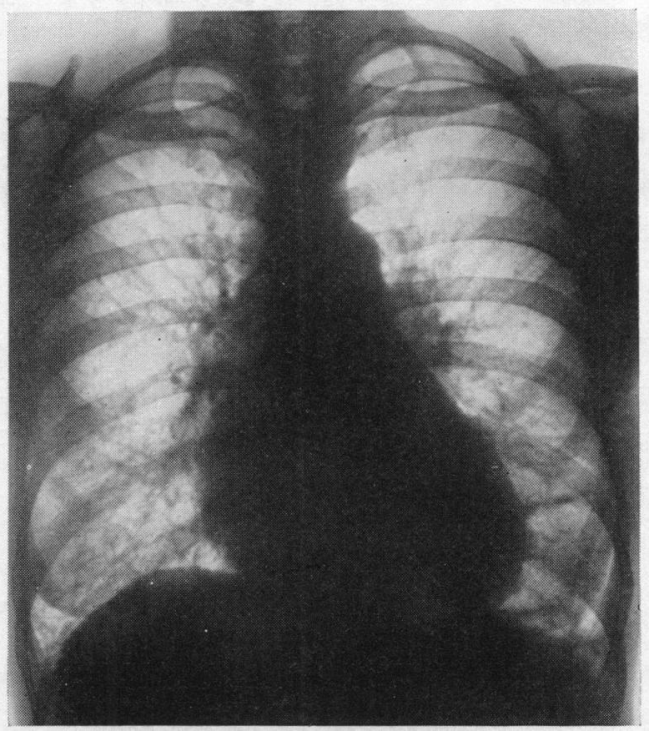

FIG. 1.-Case 1. Teleradiogram showing moderate generalized enlargement of the heart with pulmonary congestion.
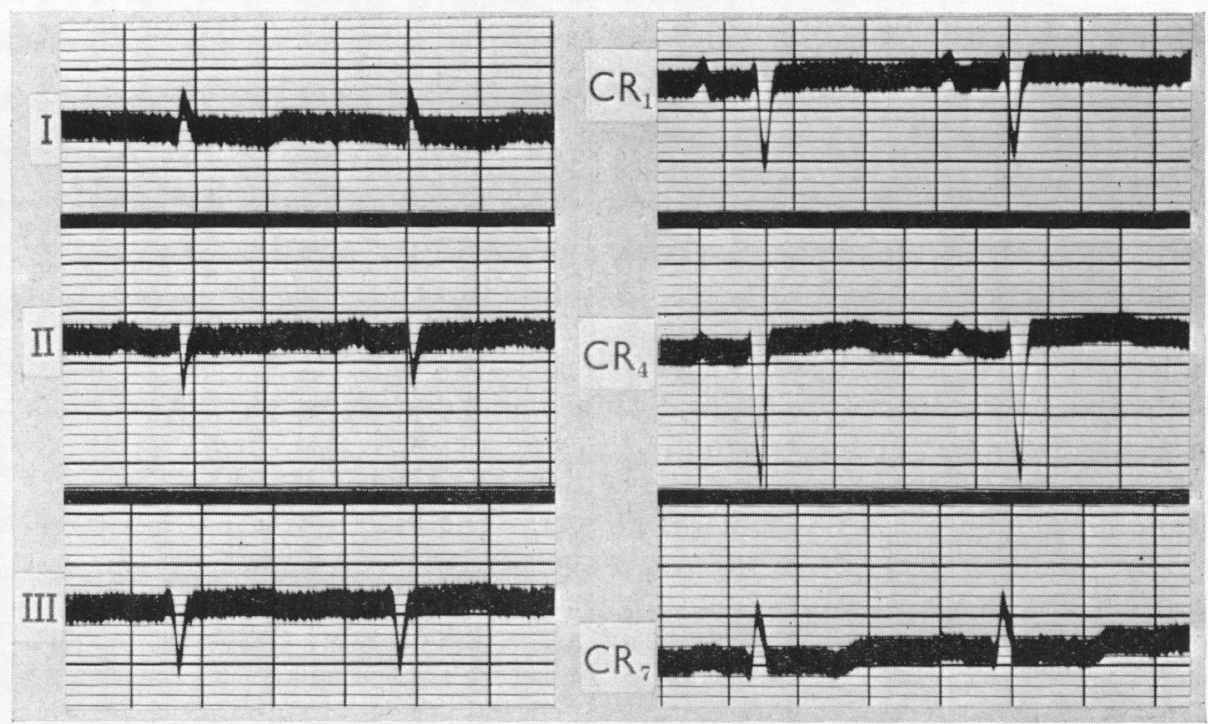

FIG. 2.-Case 1. Low voltage electrocardiogram with diphasic T wave in leads I and CR7.

\section{Summary of Necropsy (P.M. 226/47)—Heart Failure. Primary Atypical Amyloid Disease}

Heart-Slight fibrous thickening of visceral pericardium, extensive over right heart, more patchy over left heart. Hypertrophy and dilatation of right ventricle $(0.5 \mathrm{~cm}$. thick), slight of rubbery grey myocardium of left atrium but none of abnormally firm mottled red and brown myocardium of left ventricle. Smooth grey thickening of endocardium of left atrium, slight of right atrium. Recent antemortem thrombus in left auricular appendage. Valves normal. Moderate general atheroma. 
Other Organs-Partial collapse of lower lobes of œdematous lungs. Clear straw-coloured pleural effusions $(800 \mathrm{ml}$. each side). Slight induration of tongue. Reticular congestion of liver. One infarct in each congested kidney. Firm congested spleen. Slight ascites $(30 \mathrm{ml}$.). Slight thickening of parietal peritoneum. Red, partly adipose, marrow in upper three-quarters of shaft of femur. Very great pitting œdema of legs, trunk, back, and arms. Weights: heart 396 grams; liver 1300 grams; kidneys 370 grams; spleen 170 grams; body weight $73.4 \mathrm{~kg}$.

\section{Microscopical Examination}

Heart-Sections of right and left atria and ventricles, mitral and tricuspid valves and of both main branches of the left coronary artery were examined. Amyloid infiltration is present in the walls of several medium sized and small coronary arteries and in a few capillaries and veins in all the cardiac chambers. It is absent from the walls of the main branches of the left coronary but is present in a few capillaries in their adventitia. It is seen apart from vessels in the myocardium of left and right ventricles, left atrium and to a lesser extent in right atrium. It is conspicuous in epi- and endo-cardium in most sections. In the myocardium it occurs chiefly as irregular plaques (Fig. 3) but in the right ventricle irregular branching threads enclose some muscle fibres in a network. In some of the fibres loss of nuclear staining, loss of striation and vacuolation of cytoplasm indicate necrosis,'but the latter is not massive. Patches of amyloid are present in the substance of both mitral and tricuspid valves.

In sections of tongue and pharynx the amyloid appears both in the submucosa and between muscle fibres; it is also seen in the latter site in bladder, diaphragm, and psoas muscle. In these organs and also in the broad ligament, ileum, pectoral muscle, liver, spleen, kidney, and lungs infiltration of the walls of

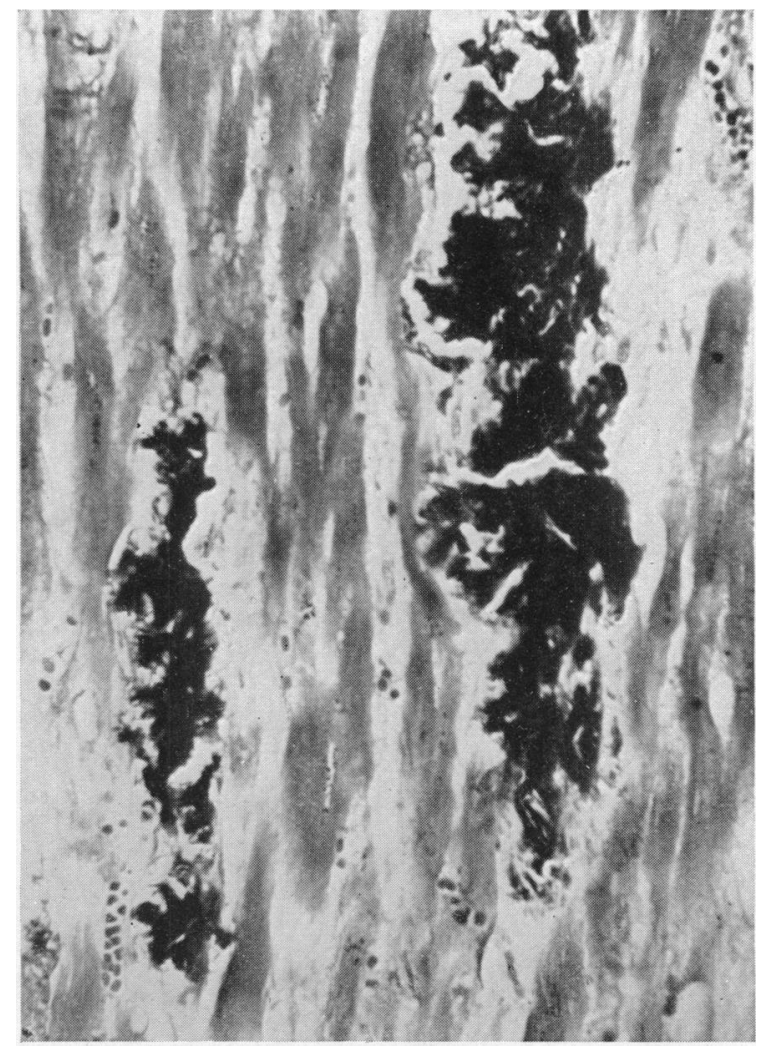

Fig. 3.-Case 1. Amyloid plaques between muscle fibres of left auricle. Crystal violet; $\times 220$ approx. 
vessels is conspicuous. These are mostly vessels of small calibre and chiefly arteries and arterioles, although in some sites, e.g. the submucosa of the bladder, small capillaries and venules appear also to be affected. It is difficult to be certain of this as the thickened vessels resemble arterioles but the absence of an internal elastic lamina and the appearance of neighbouring normal vessels suggest that some are capillaries. In the liver, arteries and arterioles of portal systems are involved; in the spleen, central arterioles of Malpighian bodies and in the kidney a few arcuate arteries, interlobulars and a very few vasa afferentia. The presence of renal infarction (presumably embolic) is confirmed but no evidence of necrosis is present in the other tissues. In the lung several bronchial and a few small pulmonary arteries are infiltrated but in only two of these is there intimal cellular proliferation. The tissues mentioned were the only ones examined except for the aorta and main pulmonary artery. In these amyloid is confined to small arterioles and capillaries in the adventitia.

Case 2. A five-year history of ill health in a woman, aged 62, began with episodes of palpitation and breathlessness associated with retrosternal pain and vomiting. On account of these symptoms she was twice admitted to another hospital, and on one occasion the electrocardiogram showed complete heart block with subsequent return to normal rhythm. For three months before her admission to hospital she had been confined to bed with dyspnœa, recurrent chest pain, and persistent heart irregularity. The signs were those of heart failure but without œdema. There were no murmurs and the blood pressure was $105 / 80 \mathrm{~mm}$. $\mathrm{Hg}$. An electrocardiogram showed auricular tachycardia with $2: 1 \mathrm{~A}-\mathrm{V}$ dissociation (Fig. 4A). Auricular fibrillation was induced with digitalis (Fig. 4B), and normal rhythm was restored within four days (Fig. 4C). She left hospital a month later on a maintenance dose of quinidine. Three years later she was again admitted complaining of occasional palpitation and increasing breathlessness. There was still no œdema, but the venous pressure was raised, the liver was distended and crepitations were present at the lung bases. The appearance of the tongue was normal. Triple rhythm was well heard at the apex, and there were no murmurs. There was no albuminuria, and the blood pressure was $130 / 85 \mathrm{~mm} . \mathrm{Hg}$. The hæmoglobin was 85 per cent and the blood count was otherwise normal. Plasma proteins were not estimated. Radiologically there was considerable generalized cardiac enlargement with

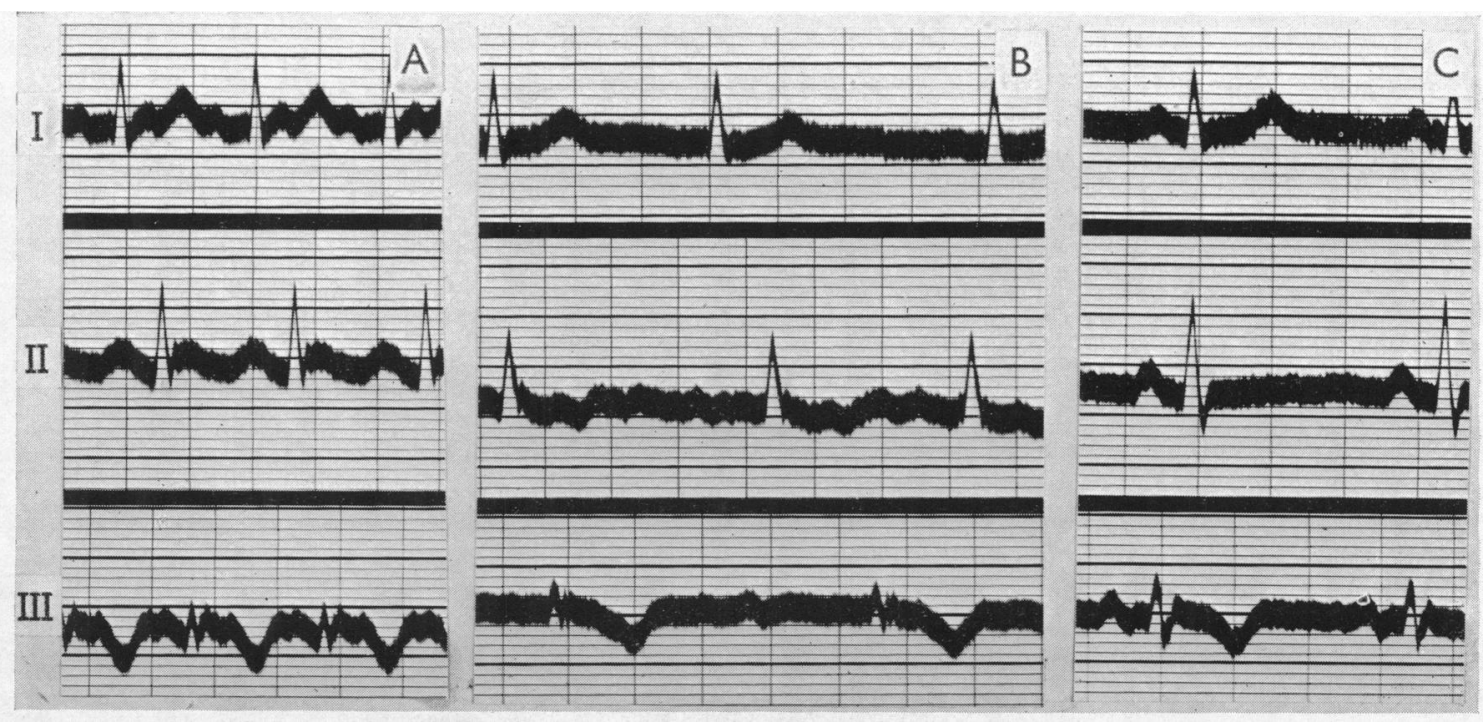

Fig. 4.-Case 2. The electrocardiogram in (A) is of moderately low voltage and shows auricular tachycardia with $2: 1$ A-V dissociation; (B) recorded 13 days later shows auricular fibrillation, and sinus rhythm returned (C) four days after withdrawal of digitalis. 
pulmonary congestion (Fig. 5). The electrocardiogram was of low voltage with the $T$ wave inverted in lead III and flattened in leads II and CR7 (Fig. 6). There was a limited response to treatment and on discharge one month later she was still moderately dyspnœic. Within three months she was again admitted with progressively severe dyspnœa aggravated two weeks previously by pulmonary infarction. The electrocardiogram now showed established auricular fibrillation with right bundle-branch block (Fig. 7). A few days later a secondary pulmonary infarct occurred from deep vein thrombosis in the left calf. Treatment was begun immediately with heparin and dicoumarol, the prothrombin index being estimated daily. On the eighteenth day diffuse skin ecchymoses appeared with the prothrombin index at 50 per cent. Anticoagulants were stopped and large doses of vitamin $\mathrm{K}$ were given, but the prothrombin index fell to 28 per cent. On the following morning she was found to have a left hemiplegia which proved fatal within a few hours.

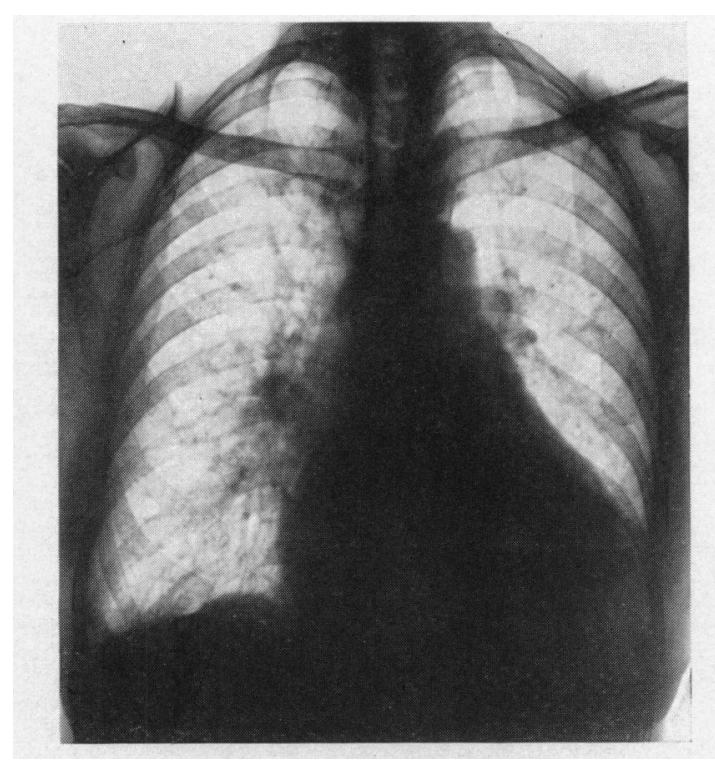

FIG. 5.-Case 2. Teleradiogram showing considerable generalized enlargement of the heart with pulmonary congestion.

\section{Summary of Necropsy (P.M. 435/47)—Cerebral Hamorrhage and scattered hamorrhages throughout body. Dicoumarol therapy. Heart Failure. Primary Idiopathic Amyloid Disease}

Heart-Recent fibrinous pericarditis with some associated petechiæ. Generalized cardiac enlargement, most pronounced in the upper posterolateral half of the left ventricle where an area, up to $2.5 \mathrm{~cm}$. thick, with a waxy appearance of grey interlacing strands between brown muscle was fairly sharply circumscribed. Remainder of left ventricle relatively flabby with a few faint grey areas on the mostly uniform brown cut surface. Moderate hypertrophy of right ventricle and of both atria. Grey thickening of endocardium of both atria and slight of mitral and tricuspid valves; slight granularity of the auricular aspect of the mitral cusps and the thickening of the tricuspid most marked in an area $(1 \mathrm{~cm}$. diam.) on right anterior cusp. Aortic and pulmonary valves normal. Moderate general atheroma of systemic arteries but slight in coronary arteries.

Other Organs - Recent infarct in right lung; collapse of lower lobe of left lung. Blood-stained effusion ( $295 \mathrm{ml}$.) in left pleural cavity. Extensive hæmorrhage in left cerebrum communicating with lateral ventricle. No visible abnormality in main cerebral arteries. Infarct in left kidney. Hæmorrhage in perirenal and retrocolic tissue. Reticular back-pressure congestion of liver with focal atrophy and regeneration. 


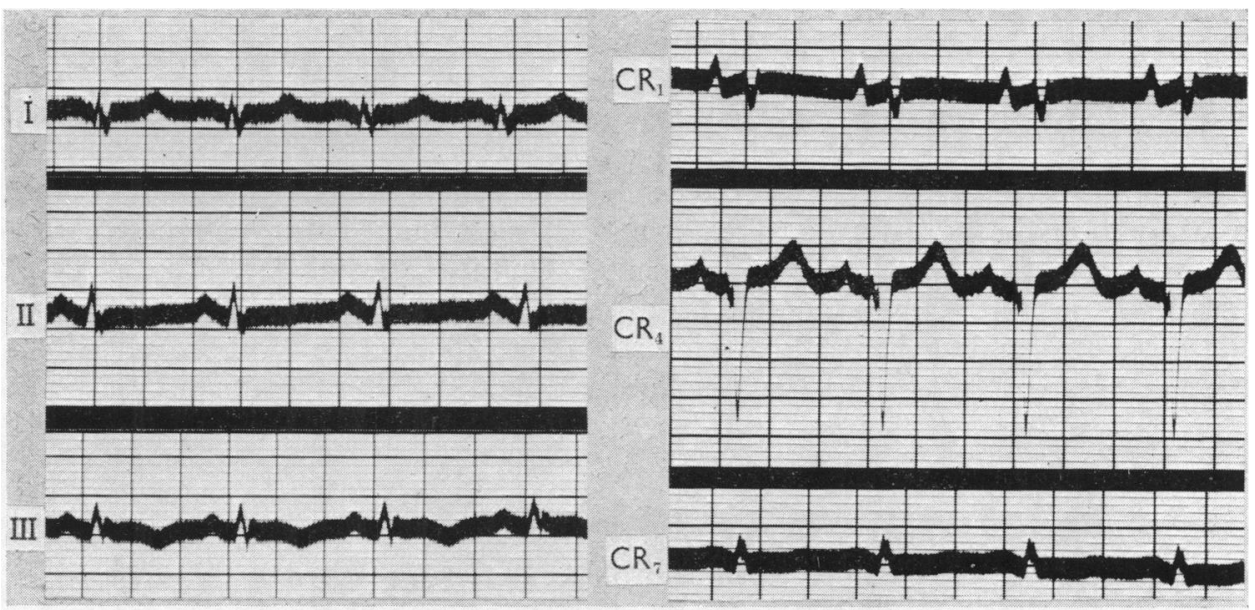

FIG. 6.-Case 2. Low voltage electrocardiogram with the T wave inverted in lead III and flattened in leads II and CR7. The patient was not receiving digitalis.

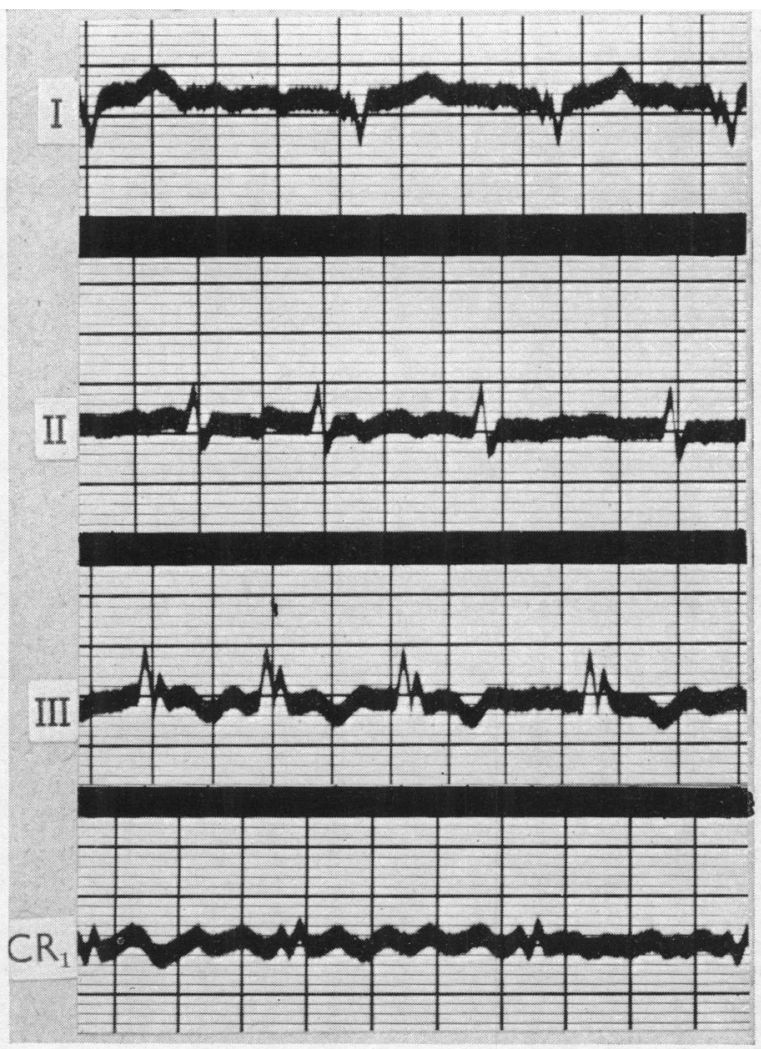

FIG. 7.-Case 2. Electrocardiogram showing established auricular fibrillation with right bundle-branch block.

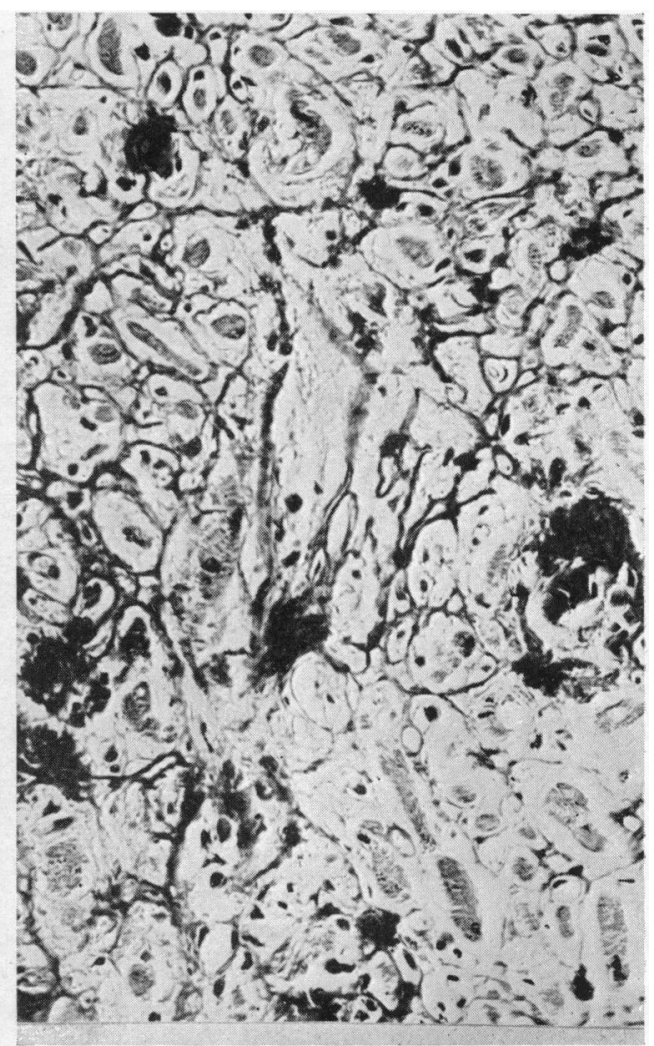

FIG. 8.-Case 2. Amyloid network enclosing partly necrotic muscle fibres of left ventricle. Congo red; $\times 230$. 
Normal tongue. Red marrow throughout vertebrae, in sternum and in patches in upper third of shaft of femur. Numerous ecchymoses in subcutis. Edema of legs and sacral pad. Slightly wasted woman. Weights : heart 532 grams; liver 1332 grams; spleen 106 grams; kidneys 205 grams; body weight 50.4 kg.

\section{Microscopical Examination}

Heart-Sections from all four cardiac chambers and mitral and tricuspid valves were examined. Amyloid is present as focal patches in the media of many medium-sized and small arteries, and in a few veins and capillaries in epi- and myocardium. From some of the vessels it extends as irregular plaques into surrounding connective tissue, separating muscle bundles. In the upper half of the posterolateral wall of the left ventricle (the area most striking to the naked eye) the amyloid forms an irregular net of fine and coarse strands which in some areas enclose muscle fibres (Fig. 8). Plaques of amyloid are present not only in this area but also in the fibrotic endocardium, the epicardium over the left atrium, and the substance of the mitral and tricuspid valves. Necrosis of many muscle fibres enclosed by the amyloid strands is indicated by loss of nuclear staining, loss of striation, and vacuolation of cytoplasm. Such necrosis is patchy and is not associated with inflammatory reaction. The only trace of the latter is an occasional foreign body giant cell accompanied by scanty lymphocytes and spindle fibroblasts around a few amyloid plaques.

Amyloid appears in the submucosa of the tongue and in minute areas in the perineurium of the sciatic nerve. In these tissues, and also in the spleen, liver, bladder, kidney, mesentery, psoas muscle, diaphragm, uterus, suprarenal, pancreas, and lung, amyloid infiltrates the walls of bloodvessels. Small and medium sized arteries are commonly involved, veins and capillaries rarely. In the kidney, arcuate and interlobular arteries are affected; in the liver, the arterioles of the portal systems, and in the spleen the central arterioles of the Malpighian bodies. Small focal plaques of amyloid are seen in the media of a main branch of a pulmonary artery within the lung and in several other arteries of all sizes in both lungs. This is associated with intimal cellular proliferation in only a very few. The only sections examined which showed no trace of amyloid were of cerebellum, frontal cortex, and bone marrow. There is no evidence of plasma cell proliferation either in the latter or in the spleen.

Case 3. A woman, aged 57, was admitted to hospital with a history of gradually progressive dyspnœa for one year and intermittent swelling of the ankles for five weeks. Two days before admission she had a severe episode of palpitation and dyspnœa lasting an hour followed by persistent vomiting. At first her general condition was fair. There was no œdema, but the neck veins were distended, the liver was easily palpable and crepitations were present at both lung bases. The pulse was regular, and the blood pressure was $110 / 70 \mathrm{~mm} . \mathrm{Hg}$. The apex beat was displaced $2.5 \mathrm{~cm}$. to the left, and there were no murmurs. The hæmoglobin was 80 per cent. The urine had a specific gravity of 1020 and contained one-fifth volume of albumin. A renal factor was suspected, and this was later confirmed histologically. Undoubted evidence of heart failure soon appeared, however, with gradually increasing dyspnœa and œdema. Energetic treatment with digitalis and mercurial diuretics produced little improvement, although the blood urea which had been $99 \mathrm{mg}$. per $100 \mathrm{ml}$. on admission fell to normal during the seventh week. At the time of her death during the tenth week extensive anasarca of the lower extremities had spread to involve the abdominal wall. Neither a chest X-ray nor an electrocardiogram are available to complete the details of this patient, but the general clinical picture was that of severe and progressive heart failure.

\section{Summary of Necropsy (P.M. 294/35)—Heart Failure. Primary Idiopathic Amyloid Disease}

Heart-Slight diffuse fibrous thickening of pericardium. Tough dry myocardium. Considerable dilatation and moderate hypertrophy of right ventricle (R.V. $0.4 \mathrm{~cm} .$, L.V. $1.5 \mathrm{~cm}$.). Great dilatation of right atrium, less of left. Moderate atheroma.

Other Organs-Congestion of liver. Moderate enlargement of hard, rubbery spleen with loss of pattern on flat, dry cut surface. Slightly enlarged firm kidneys. Edema and congestion of lungs. Multiple serous effusions with coagula (ascites $590 \mathrm{ml}$.; left pleura $60 \mathrm{ml}$.; right pleura $180 \mathrm{ml}$; pericardium $30 \mathrm{ml}$.). Brownish red, partly adipose marrow in neck and upper two-thirds of shaft of femur. Slight jaundice of skin and of conjunctivæ. Gross pitting œdema of legs and thighs. Weights: heart 368 grams; liver 2411 grams; kidneys 368 grams; spleen 255 grams; body weight $55 \cdot 8 \mathrm{~kg}$. 


\section{Microscopical Examination}

Heart - Only the right and left ventricles were examined. These show widespread deposition of amyloid between muscle fibres, chiefly as patches but in places as irregular strands. Plaques are frequent in the walls of the smaller coronary vessels and in a few are associated with an adjacent intimal proliferation which narrows the lumen considerably. Some diffuse fibrosis of the myocardium is associated with these changes and in a frozen section of the left ventricle there are numerous fine sudanophil droplets in the muscle fibres.

Other Organs - In the kidney small deposits of amyloid are present in about a third of the glomerular tufts, in a few vasa afferentia and interlobular arteries, in several arcuate arteries and a few vasa recta. Widespread parenchymatous and some fatty degeneration affects the tubules of the cortex; hyaline droplet change is seen in a few. Hyaline, granular and a few fatty casts are present in their lumina. The spleen is extensively infiltrated by amyloid. Sinuses are still evident, but no other trace of a pattern is left and only small groups of lymphocytes are scattered in the hyaline amyloid background. In the stomach and jejunum amyloid replaces some muscle fibres and is present in the small arteries of the submucosa. In the suprarenal it is restricted to similar vessels in the capsule, and in the liver to the arterioles of the portal system.

Severe reticular congestion is present in the liver, together with central atrophy of lobules, extensive fatty change of parenchyma and some regeneration as indicated by numerous binucleate cells. The only other organs examined were the upper lobe of the right lung which is free from amyloid and the pancreas where only a very few small arteries are infiltrated.

Case 4. A woman, aged 46, was admitted to hospital because of progressive breathlessness for five months followed by swelling of the ankles. On examination, the feet were not swollen but there was moderate pitting œdema in the sacral area. The neck veins were slightly distended, the liver edge was palpable four fingers' breadth below the costal margin and there were signs of pulmonary congestion with a small right hydrothorax. The pulse was regular and the blood pressure was $130 / 90 \mathrm{~mm}$. $\mathrm{Hg}$. There were no murmurs. The apical second sound was recorded as being noticeably split. The tongue and fauces appeared normal. The urine was normal. The electrocardiogram showed right bundle-branch block with moderately low-voltage complexes, and a short $\mathrm{Q}$ wave in leads I and CR4 was indicative of anterior cardiac infarction (Fig. 9). Radiologically there was considerable generalized cardiac enlargement with a small hydrothorax on the right side. On fluoroscopy the pulsation of the heart was greatly diminished, and this accounted for the stencilled cardiac outline in the X-ray film (Fig. 10). There was no evidence of pericardial calcification. A complete blood count, E.S.R. and a full range of liver function tests gave normal results. Although the heart was enlarged and pericardial calcification was absent, the association of a quiet heart on fluoroscopy with distension of the liver and neck veins suggested constrictive pericardial disease. A period of treatment with digitalis, mercurial diuretics, and a restricted intake of fluids and sodium was observed before deciding upon operation. These measures met with no success. The pleural effusion required aspiration on two occasions, and when she left hospital after a stay of four months her condition was unchanged. Although confined to bed under the care of her own doctor she became increasingly breathless and was re-admitted six months later. She was by now slightly cyanosed and there was considerable œdema of the legs and sacral area. The liver edge was palpable five fingers' breadth below the costal margin and there was evidence of ascites. Moist crepitations were heard in both lungs and there were signs of a large pleural effusion on the right side. X-rays showed that a smaller effusion was also present on the left side. There were no murmurs, and the electrocardiogram showed no further change from the previous tracing. With the patient supine the venous pressure measured at the arm was $17 \mathrm{~cm}$. saline above the sternal angle. Blood counts and liver-function tests were normal as before. The serum protein level was $6.5 \mathrm{~g}$. per $100 \mathrm{ml}$. (albumin 4.0 grams, globulin 2.5 grams). In spite of the conflicting evidence afforded by the chest $\mathrm{X}$-ray and electrocardiogram, constrictive pericardial disease was still thought to be the most likely diagnosis. It was therefore decided to submit the patient to thoracotomy. At operation, however, the pericardium presented a normal appearance and subsequent examination of biopsy material was negative. There was considerable enlargement of the heart as a whole, and its range of movements was observed to be greatly diminished. In the days 


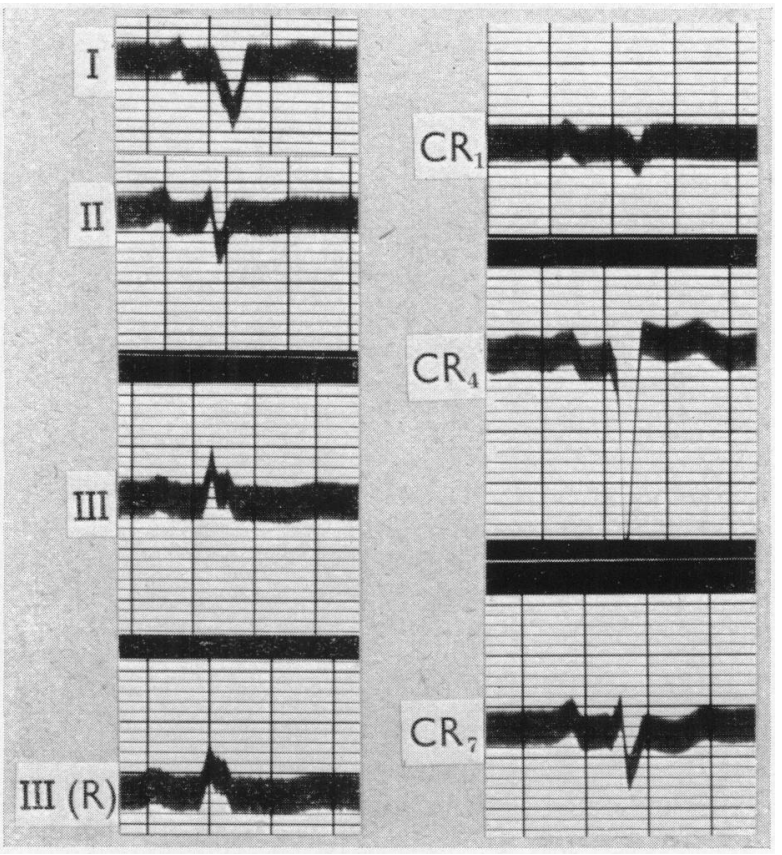

FIG. 9.-Case 4. Moderately low voltage electrocardiogram with right bundle-branch block. A short $Q$ wave in leads I and CR4 suggests anterior cardiac infarction. The patient was receiving digitalis.

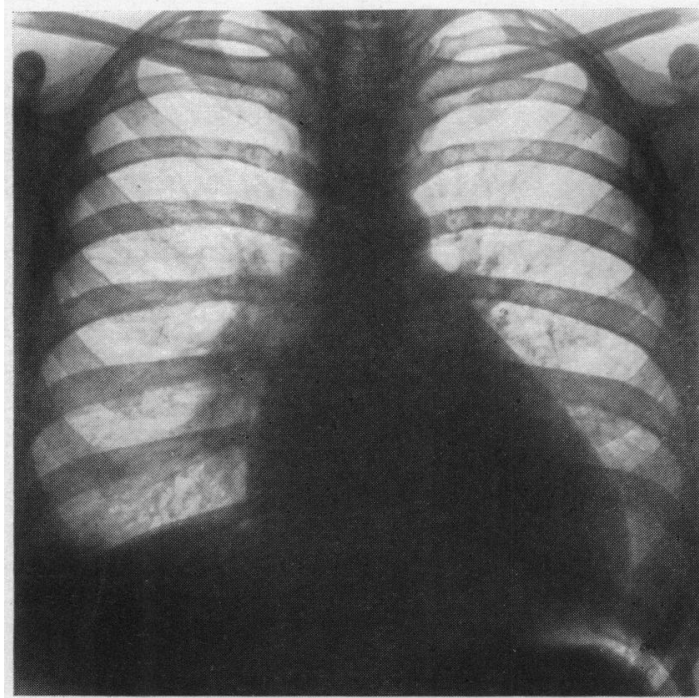

FIG. 10.-Case 4. Teleradiogram showing considerable generalized cardiac enlargement with pulmonary congestion and a small hydrothorax. The outline of the heart has a stencilled appearance which is due to greatly diminished cardiac pulsation.

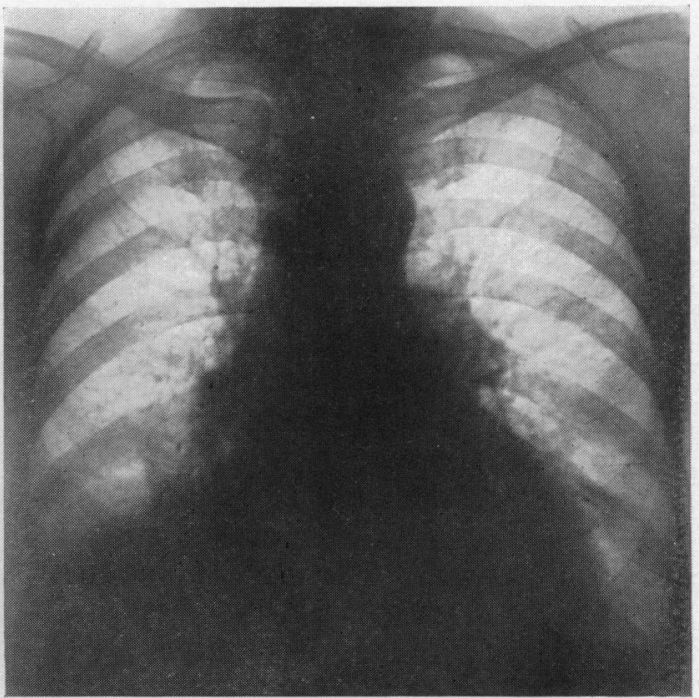

FIG. 11.-Case 5. Teleradiogram showing moderate cardiac enlargement with pulmonary congestion and a small hydrothorax. 
which followed her condition steadily worsened and became further complicated by venous thrombosis arising in the right leg. She died suddenly from pulmonary embolism on the seventeenth day after the operation.

\section{Summary of Necropsy (P.M. 58/51)-Pulmonary Embolism. Chronic Heart Failure. Primary Idiopathic Amyloid Disease. Recent Operation-Pericardotomy}

Antemortem thrombus $(10 \mathrm{~cm}$. long and up to $1.5 \mathrm{~cm}$. diam.) in main pulmonary artery. Similar thrombus in right femoral vein.

Heart-Partly organized fibrinous exudate loosely uniting visceral and parietal pericardium. Operative defect $(5 \times 2.5 \mathrm{~cm}$.) in left side of parietal pericardium. Diffuse hypertrophy of myocardium of whole heart but more obvious in ventricles (L.V., $1.8 \mathrm{~cm}$.; R.V., $0.8 \mathrm{~cm}$. thick). Antemortem thrombus in auricular appendages. Irregular area of yellow necrosis, approximately $4 \mathrm{~cm}$. from above down and $1-1.5 \mathrm{~cm}$. diam. surrounded by grey, glistening zone, up to $0.8 \mathrm{~cm}$. thick, in upper half of lateral wall of left ventricle. Firm, red myocardium elsewhere. Patches of greyish-white subendocardial fibrosis in both auricles, none in ventricles. No fibrosis of pericardium. Very slight thickening of free edge of junction of anterior and posterior cusps of mitral; remaining valves normal. Slight atheroma.

Other organs-Reticular congestion of liver. Firm congested spleen. Congested kidneys. Hæmorrhagic infarcts in congested lungs. Patches of fibrinous exudate over pleura of both lungs. Clear brown pleural effusions $(1050 \mathrm{ml}$. right, $60 \mathrm{ml}$. left) ; clear fluid $(360 \mathrm{ml}$.) in peritoneal cavity. Brick red, partly adipose marrow in upper $21 \mathrm{~cm}$. of 34-cm. shaft of femur; similar marrow in sternum. Well-healed scar, $30 \mathrm{~cm}$. long, in skin over left side of chest. Edema of right leg, slight of left. Slightly wasted woman. Weights : heart 610 grams; liver 1644 grams; kidneys 360 grams; spleen 135 grams; body weight $51 \cdot 8 \mathrm{~kg}$.

\section{Microscopical Examination}

Heart-In this example the most striking feature is the area of necrosis in the left ventricle. Muscle fibres in which nuclei have disappeared, but in which longitudinal striation is still present, are conspicuous. These blend imperceptibly with an ill-defined eosinophil matrix in which the only suggestion of structure is an occasional vessel and some longitudinal strands. It is possible that the latter represent collapsed sarcolemmal sheaths. This matrix fails completely to react with stains for amyloid and collagen although the walls of small vessels in and about it are positive to Congo red. It is therefore interpreted as complete necrosis, and the adjacent area with some residual striation in fibres as a zone of partial necrosis. Although no thrombus was detected in any major coronary vessel at necropsy, many of the smaller arteries and veins, with amyloid deposited in their walls, show intimal cellular proliferation with great reduction of their lumina. It appears that ischæmia from this stenosis of small vessels is the cause of the necrosis. A surprising feature is the extremely scanty inflammatory reaction in and around the necrosis; it is represented by a very few small collections of polymorphonuclear and mononuclear cells. These findings suggest that the ischæmia was relatively slow, and provide a possible explanation for the absence of cardiac pain. Apart from this area, amyloid is conspicuous in the walls of small arteries and veins in all cardiac chambers, but is less extensive outside vessels than in Cases 1,2, and 3. There are a few small patches in the substance of the mitral valve.

Elsewhere, amyloid is present as scanty patches between the muscle fibres of the tongue, in its submucosa, and as rings around the basement membranes of acini of mucous glands. In the stomach there are irregular patches in the deep part of the mucosa. In the pancreas there is extensive infiltration between lobules, and the walls of vessels are affected more severely than in the tongue and stomach. Infiltration is restricted to vessel walls in the body of the uterus, lungs, kidney, suprarenals, bladder, psoas muscle, ileum, mesentery, liver, and spleen. Arteries are affected more frequently than veins or capillaries. The only tissues examined in which amyloid is not found are the cerebellum, pituitary, a lymph gland, and bone marrow. There is no unusual plasma cell proliferation in either of the two latter tissues or in the spleen. Other findings are conspicuous central congestion of the liver and hæmorrhagic infarction in the lung.

Case 5. A woman, aged 63, was admitted to hospital with a history of progressive breathlessness, intermittent ankle œdema, and epigastric discomfort over the past year. Latterly the œdema had extended to the knees and dyspnœa had become severe. On examination there was slight 
cyanosis, pitting œdema of the legs and sacral area, distension of the neck veins, evidence of pulmonary congestion and slight enlargement of the liver. The pulse was regular and the blood pressure $110 / 70 \mathrm{~mm}$. Hg. The heart sounds were distant and there were no murmurs. The tongue presented a normal appearance apart from some anterior fissuring. The urine contained one-fifth volume of albumin and the specific gravity was 1015. A differential blood count was normal and the hæmoglobin was 85 per cent. The serum protein level was $5 \cdot 2 \mathrm{~g}$. per $100 \mathrm{ml}$. X-rays showed that there was moderate cardiac enlargement with pulmonary congestion and a small right hydrothorax (Fig. 11). An electrocardiogram was not recorded. Renal function tests soon after admission showed a marked diminution in P.S.P. excretion, and although the blood urea was found to be only $45 \mathrm{mg}$. per $100 \mathrm{ml}$. the heart failure was thought to be secondary to chronic nephritis. Treatment with digitalis, however, resulted in the disappearance of edema, reduction of albuminuria to a faint haze and improvement in P.S.P. excretion to 53 per cent in two hours. The diagnosis was amended to one of primary cardiac failure, and after five weeks the patient was discharged from hospital. Her breathlessness and cedema gradually returned, and three months later a violent attack of dyspnea with collapse led to her urgent readmission. She died twelve hours later.

\section{Summary of Necropsy (P.M. 44/47)—Heart Failure. Primary Atypical Amyloid Disease}

Heart-Considerable hypertrophy of ventricles: L.V., $2 \mathrm{~cm}$.; R.V., $0.7 \mathrm{~cm}$. thick; and of left atrium, $0.4 \mathrm{~cm}$. thick. (No note of the texture of the myocardium or of the pericardium or endocardium was made at necropsy: the diagnosis was made only on histological examination.) Moderate general atheroma.

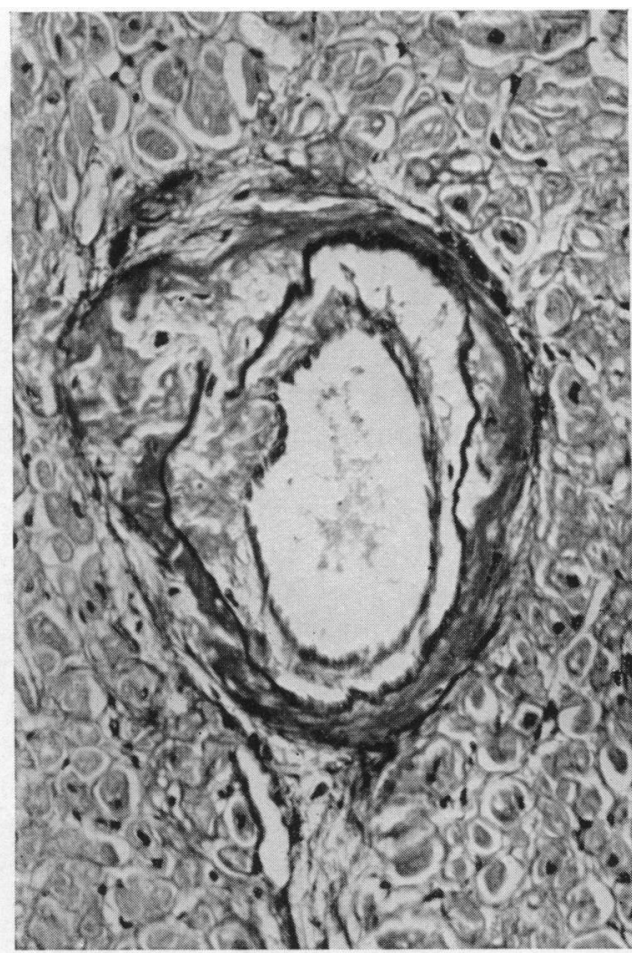

Fig. 12.-Case 5. Amyloid in media of small coronary artery; œdematous thickening of the intima with scanty amyloid. Verhoff; $\times 200$. (The dark areas react positively in a Congo red stain.)

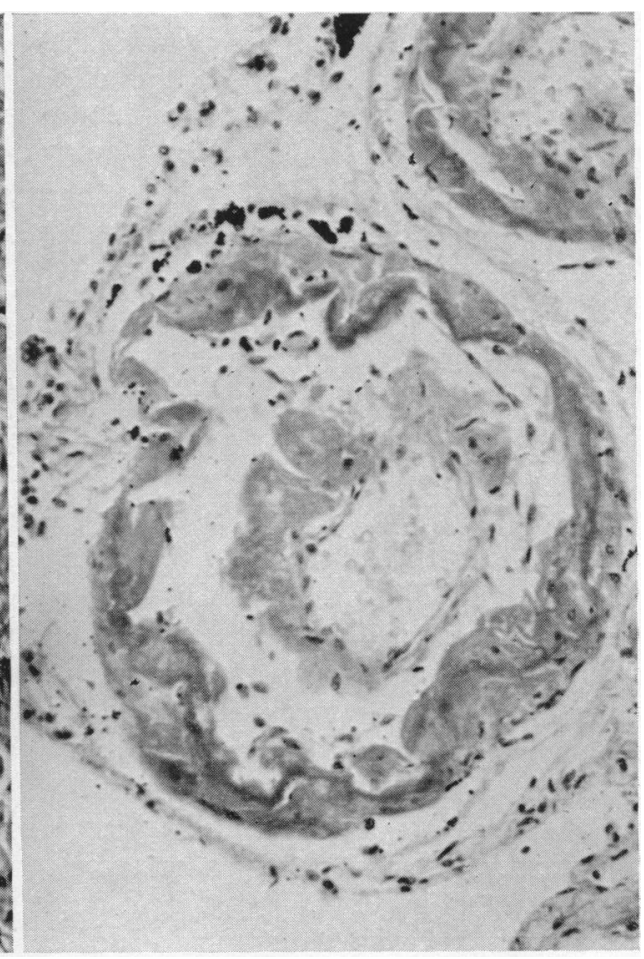

Fig. 13.-Case 5. Small pulmonary artery. Amyloid in media and intima. Edematous thickening of intima with considerable reduction of lumen. Congo red; $\times 195$. 
Other organs-Clear pleural effusions $(1950 \mathrm{ml}$. right, $1240 \mathrm{ml}$. left). Congestion of rather dry, poorly aerated lungs. Collapse of lower half of left lower lobe, lower and anterior angle of left upper lobe, lower half of right lower lobe, the whole of the right middle lobe and lower and anterior third of right upper lobe. Reticular congestion of liver. Congestion of spleen. A few small pits of ischæmic atrophy on very faintly granular surface of congested kidneys. Fibrous adhesions about liver and spleen. A few patches of red, fatty marrow in upper half of shaft and neck of femur. Edema of lumbar region and ankles. Wellnourished woman. Weights : heart 645 grams; liver 1815 grams; kidneys 404 grams; spleen 200 grams ; body weight $60 \mathrm{~kg}$.

\section{Microscopical Examination}

This was limited to the right and left ventricles, the lower lobe of the right lung, the right kidney and the right radial artery.

Heart-Amyloid infiltration is present in the walls of several smaller coronary arteries and veins. In a few of the infiltrated arteries there is a further œdematous thickening of the intima with considerable reduction of their lumina (Fig. 12). Amyloid is nearly always absent in such an intima; collagen fibrils and cells are also extremely scanty. Apart from the vessels amyloid is not extensive in the myocardium, but a few plaques and a few irregular strands are present. There is, however, no evidence of necrosis of muscle fibres. In the single lung section available amyloid infiltration is extensive. It affects the walls of many arteries and veins, and small patches are present in several alveolar capillaries. In affected arteries, the deposit is usually in the media, and is conspicuous adjacent to the internal elastic lamina. It may, however, extend focally into the intima, and in some vessels the elastic is partly destroyed so that the localization of the infiltration is difficult. Many of the infiltrated arteries have a further odematous thickening of the intima in which only a few fibroblasts or small round cells are present, similar to that seen in coronary arteries and producing stenosis (Fig. 13). The lung parenchyma is collapsed.

In the kidney amyloid is present in several arcuate and interlobular arteries and in vasa afferentia but not in vasa recta. About half of the glomeruli show small focal deposits similar to those seen in Case 3, but the extensive infiltration and obliteration of glomerular tufts so common in secondary amyloidosis is not seen. Parenchymatous degeneration of tubules is widespread and several contain hyaline casts.

\section{Discussion}

Primary amyloidosis is said to differ from the more commonly encountered secondary form in that deposits are found chiefly in cardiac, skeletal, and smooth muscle, and only very slightly in the liver, spleen, kidneys, and adrenals. Although occasional overlap in distribution between the two forms shows that this distinction is not strictly valid, it is only in primary amyloidosis that the heart may be chiefly affected. Since routine post-mortem examination may fail to yield the correct diagnosis, we believe the disease to be less rare than would appear from a study of previously reported cases.

The recorded age distribution lies between 24 and 90 years (Higgins and Higgins, 1950). Most cases occur in the sixth and seventh decades, and in our series the average age at the onset of symptoms was 55 years. This contrasts with the much earlier incidence of secondary amyloidosis. The sex distribution is reported to be about equal (Eisen, 1946), but all our patients were women.

Since the primary form of amyloidosis most commonly presents with heart failure, special emphasis is laid on this important aspect of the disease. Dyspncea on exertion was the main complaint of our five patients and it was the initial symptom in all but one (Case 2) who presented with paroxysmal tachycardia. Similarly, anasarca was present in all except Case 2 in whom the natural course of the disease was prematurely terminated by cerebral hæmorrhage complicating dicoumarol treatment. Anginal pain was never present, and is almost unknown in cardiac amyloidosis. A variable degree of generalized cardiac enlargement was always found, and the average weight of the hearts at necropsy was $\mathbf{5 1 0}$ grams. Cardioscopy showed sufficiently diminished pulsation of the heart in one patient (Case 4) to suggest constrictive pericardial disease. Two other cases have been reported in which this diagnosis was made during life, and in one of these a fruitless thoracotomy was similarly undertaken (Findley and Adams, 1948; Couter and Reichert, 1950). Triple rhythm was noted in two patients. As in most other reported cases, murmurs were conspicuously absent. 
Hypotension was present in three patients, and this feature has been emphasized by other authors (Kerwin, 1936; Koletsky and Stecher, 1939; Binford, 1940; Kalbfleisch, 1940; Soisalo and Ritama, 1944; Eisen, 1946; Ranström, 1946; Baber, 1947). Normal rhythm was found in four patients, though in one of these a transient phase of auricular fibrillation was observed; in the remaining patient (Case 2) auricular fibrillation became established. An electrocardiogram was recorded in three patients, and the tracings were all of low voltage, with a diphasic $T$ wave in leads I and CR7 (Case 1) or right bundle-branch block (Cases 2 and 4). The cardiographic changes in Case 2 deserve special metion because the observed sequence of paroxysmal tachycardia, transient complete heart block, sinus rhythm, and finally established auricular fibrillation with right bundle-branch block has not hitherto been described in cardiac amyloidosis. Case 4 was also quite exceptional in that, in spite of the absence of cardiac pain, a zone of necrosis was found in the lateral wall of the left ventricle at necropsy which accounted for the $\mathrm{Q}$ wave in leads I and CR4 of the electrocardiogram. The tracings in previously reported cases have most frequently been of low voltage with normal rhythm and a low, diphasic or inverted $\mathrm{T}$ wave in lead I and the left præcordial leads. These changes may sometimes resemble those recorded in ischæmic heart disease, but in their degree and distribution they seldom conform fully to those accompanying heart failure from antecedent cardiac infarction. While differentiation may be impossible, particularly when evidence of infarction is suppressed by bundle-branch block, it is considered that the presence of inadequate changes in the electrocardiogram of a patient with chronic unexplained heart failure should always suggest the possibility of cardiac amyloidosis. Auricular fibrillation and conduction defects have occasionally been described (Larsen, 1930; Josselson and Pruitt, 1953). Disturbances of conduction have been limited for the most part to bundle-branch block, but prolongation of the P-R interval (Dillon and Evans, 1942), 2 : 1 heart block (Götze and Krücke, 1941) and complete heart block (Dahlin and Edwards, 1949; Josselson and Pruitt, 1953) have been noted in a few instances. Examination of the urine showed up to onefifth volume of albumin in three cases, nothing abnormal being found in the remaining two. In contrast to secondary amyloidosis renal involvement in the primary form is usually minimal though present histologically (as in Cases 3 and 5) in about half the reported instances (Lindsay, 1948). A few cases of the " nephrotic syndrome" have been reported, and such a patient having extensive renal and cardiac amyloidosis was omitted from this series since the extreme anasarca was thought to be due to a combination of both factors. Blood examination in our patients was usually unrewarding, the average hæmoglobin being 88 per cent. The total serum protein was within physiological limits in the three patients in whom it was evaluated though in two it was at the lower level of normal. The albumin-globulin ratio was estimated in two patients, and in one (Case 1) the albumin fraction was exceeded by the globulin. In his review of 46 cases Eisen (1946) found normal values in the nine instances where the serum protein had been recorded, but considered moderate hypochromic anæmia to be a fairly consistent feature. The Congo red test is rarely positive, and this may be due to the fact that as judged by histological examination the amyloid in the primary form has less affinity for this dye than in the secondary form. In addition, the amyloid collectively may be insufficient to give a positive result.

None of our cases exhibited any of the non-cardiac manifestations so often described in the primary form of amyloidosis. Of these the most important is macroglossia, the incidence of which is as high as 42 per cent at necropsy (Eisen, 1946). In view of its reported frequency as a prominent and easily recognizable feature it is surprising that Baber (1947), in describing such a case which one of us was fortunate enough to see with her, could find only three previous instances on record in this country (Weber et al., 1937; Barnard et al., 1938). In the present series slight induration of the tongue from amyloid infiltration was noted once at necropsy (Case 1), and it would seem that even in the absence of macroglossia careful palpation of the tongue and adjacent muscles may sometimes yield important information in patients with unexplained heart failure. Skin deposits and purpuric manifestations are said to occur in about one-quarter of the cases, and this aspect of the disease has been fully reviewed by Goltz (1952). The lymph glands are moderately 
enlarged in 27 per cent of cases (Higgins and Higgins, 1950), and are involved histologically in 37 per cent (Eisen, 1946). Short of biopsy, however, this feature is of little material help in diagnosis. The skeletal muscles are affected histologically in 41 per cent of cases (Eisen, 1946), and widespread deposits may rarely lead to progressive muscular weakness (Weber et al., 1937). Similarly, extensive involvement of smooth muscle in the gastro-intestinal tract has led in a few cases to dysphagia, abdominal pain with constipation or diarrhœa, and even the sprue syndrome with hypocalcæmia (Findley and Adams, 1948). Neuropathy from involvement of peripheral nerves has also been reported (De Navasquez and Treble, 1938; Kernohan and Woltman, 1942; Strich and Wade, 1953). Enlargement of the liver and spleen from amyloid deposition is considered to be atypical in the primary form of amyloidosis. The liver was certainly enlarged in all our patients but post-mortem examination showed this always to be due to heart failure. The spleen was never palpable during life, though in one instance (Case 3) it was found at necropsy to be moderately enlarged from amyloid deposition.

The time of survival after the onset of symptoms in our cases varied between 14 months and five years, and in general the disease was observed to run a more protracted course than would be expected from the degree of cardiac disablement present. The average survival time of 32 months, happens to coincide exactly with that of the 46 cases of primary amyloidosis reviewed by Eisen (1946) in which heart failure was stated to be the usual cause of death.

In four of the present five cases the involvement of the myocardium was conspicuous and sufficient to explain cardiac failure through mechanical interference with normal heart action as in constrictive pericardial disease (Fishberg, 1940). In Case 5, however, the infiltration of the myocardium was less extensive, and it is probable that involvement of the lungs was a factor. Only one section was available but in this there was considerable amyloid in vessels and some alveolar walls. Associated with the infiltration of smaller pulmonary arteries and arterioles there was often seen a peculiar œdematous intimal thickening with great reduction in their lumina (Fig. 13). A similar thickening was also seen in a few infiltrated coronary arteries. Its nature is uncertain but the fact that it occurred in both coronary and pulmonary arteries, and only in those with amyloid in their walls, indicates that it is a reaction to the presence of amyloid and not a result of any changes in circulatory dynamics. It is therefore regarded as an unusual form of endarteritis fibrosa producing obstruction to the pulmonary circulation. It is thus necessary to remember the primary form of amyloidosis as a rare cause of pulmonary heart disease (Sappington et al., 1942).

The general distribution of the amyloid infiltration in these cases has been reviewed by Lindsay (1946). The points exemplified in the present series are the extensive but variable deposition of amyloid in the walls of blood vessels in the interstitial tissue of the heart; the infiltration, apart from vessels, in the alimentary tract and a few other organs containing smooth muscle, and very occasionally in nerves and voluntary muscles. In the heart there was no tendency for any one chamber to be especially affected, but the subendocardial zone was often extensively infiltrated. There was no involvement of liver and adrenals outside vessels, but the spleen was extensively infiltrated in one instance. In two cases there was infiltration in the kidney additional to that in the medium-sized arteries (the latter being present in all five). There was thus an overlap of distribution with that in secondary amyloidosis, and we concur with Dahlin (1949) that of all criteria given for the diagnosis of primary amyloidosis the absence of pre-existing or ætiological disease is the only constant clinical and pathological finding.

Of the 71 cases reviewed by Higgins and Higgins (1950) only 14 were recognized during life; and of these the diagnosis was established in 12 by biopsy of muscle, tongue, liver, skin, ear, nasal mucosa, or lymph glands. The correct diagnosis was made only at necropsy in four of our cases, and in the fifth only on histological examination. We would suggest that the following points are useful at necropsy examinations. It is most important to remember the possibility of amyloid disease in unexplained heart failure, and to apply the iodine test even if no other indication is present. The presence of a tough texture, a dry cut surface or a dull, waxy appearance in the myocardium is helpful, as are unexplained thickenings in the endocardium or visceral pericardium. 
Thickening or deformities of valves which are not typical of chronic endocarditis may also occasionally suggest the diagnosis. More rarely, induration of other organs may provide direct information as did the typical amyloid spleen in Case 3. As is common in the primary form of amyloidosis the staining in the present material was variable, but we obtained some reaction with the accepted methods in all five cases, the avidity for Congo red being more consistent than metachromasy.

\section{SUMMARY}

Five cases of cardiac amyloidosis are described, and their clinical and pathological features discussed.

Recognition during life is difficult, but we believe the diagnosis should be considered when otherwise unexplained heart failure, especially with normal rhythm and hypotension, is accompanied by an electrocardiogram showing equivocal changes in the $\mathrm{T}$ wave or defects in conduction.

Cardiac amyloidosis may occasionally simulate constrictive pericardial disease.

The extensive but variable deposition of amyloid seen in tissue at necropsy is described, and overlap in distribution between the primary and secondary forms of the disease is confirmed.

Attention is drawn to a secondary endarteritis that may involve the smaller coronary or pulmonary vessels having amyloid in their walls, and rarely may cause myocardial necrosis or pulmonary heart disease.

Suggestions are made concerning the recognition of cardiac amyloidosis at necropsy.

It is a pleasure to acknowledge the very helpful advice and criticism which we have received from Dr. William Evans and Professor Dorothy Russell. We are indebted to Sir Alun Rowlands, Sir Russell Brain, Dr. William Evans, and Dr. Kenneth Perry for permission to publish accounts of the cases under their care. Our thanks are also due to Mr. William Dicks, Mr. John King, Mr. Ernest Sheppard, and Miss S. Davies for technical help.

\section{REFERENCES}

Baber, M. (1947). Lancet, 1, 210.

Barnard, W. G., Smith, F. B., and Woodhouse, J. L. (1938). J. Path. Bact., 47, 311.

Binford, C. A. (1940). Arch. Path., 29, 314.

Couter, W. T., and Reichert, R. E. (1950). Circulation, 2, 3, 441.

Dahlin, D. C. (1949). Amer. J. Path., 25, 105.

, and Edwards, J. E. (1949). Proc. Staff Meetings of the Mayo Clinic, 24, 89.

De Navasquez, S., and Treble, H. A. (1938). Brain, 61, 116.

Dillon, J. A., and Evans, L. R. (1942). Ann. intern. Med., 17, 722.

Eisen, H. N. (1946). Amer. J. Med., 1, 144.

Findley, J., and Adams, W. (1948). Arch. intern. Med., 81, 342.

Fishberg, A. M. (1940). Heart Failure. 2nd ed., Henry Kimpton, p. 600.

Goltz, R. W. (1952). Medicine, Baltimore, 31, 381.

Götze, W., and Krücke, W. (1941). Arch. Psych., 114, 183.

Higgins, W. H., and Higgins, W. H. (1950). Amer. J. med. Sciences, 220, 610.

Josselson, A. J., and Pruitt, R. D. (1953). Circulation, 7, 2, 200.

Kalbfleisch, H. H. (1940). Frankfurt. Ztschr. Path., 54, 319.

Kernohan, J. W., and Woltman, H. W. (1942). Arch. Neurol. Psychiat., Chicago, 47, 132.

Kerwin, A. J. (1936). J. Lab. Clin. Med., 22, 255.

Koletsky, S., and Stecher, R. M. (1939). Arch. Path., 27, 267.

Larsen, R. M. (1930). Amer. J. Path., 6, 147.

Lindsay, S. (1946). Amer. Heart J., 32, 419.

-, (1948). Amer. J. Med., 4, 765.

Ranström, S. (1946). Acta med. Scand., 123, 111.

Sappington, S. W., Davie, J. H., and Horneff, J. A. (1942). J. Lab. Clin. Med., $27,882$.

Soisalo, P., and Ritama, V. (1944). Acta med. Scand., 116, 260.

Strich, S. J., and Wade, G. (1953). Lancet, 2, 70.

Weber, F. P., Cade, S., Stott, A. W., and Pulvertaft, R. J. V. (1937). Quart. J. Med., 6, 181.

Wild, C. (1886). Beitr. path. Anat. allg. Path., 1, 177.

Wilks, S. (1856). Guy's Hosp. Rep., 2, 105, Series 3. 